\title{
Life Satisfaction and the UEFA EURO 2016: Findings from a Nation-Wide Longitudinal Study in Germany
}

\author{
Michael Mutz ${ }^{1}$
}

Received: 11 May 2017 / Accepted: 12 February 2018 / Published online: 24 February 2018

(C) The Author(s) 2018. This article is an open access publication

\begin{abstract}
Research on sport events and well-being yield inconclusive results with some studies suggesting that well-being is increasing during major sport events while other studies fail to establish such a relationship. The present study aims at investigating the relationship between sport events and life satisfaction more closely, while at the same time avoiding some methodical pitfalls of prior research. The study uses a representative sample from Germany and had a longitudinal design, covering the time before, during and after the UEFA EURO 2016. Findings demonstrate a significant increase in life satisfaction in Germany during the football competition $(d=.17)$. Further analyses reveal that satisfaction with life is elevated particularly among subjects with a genuine interest in football in general and in the EURO in particular, whereas for those respondents uninterested in football, changes in life satisfaction were mostly insignificant and marginal in size. However, two months after the EURO life satisfaction was already on the decline and drifted towards the baseline level. Hence, the EURO did not produce a persistent change, but rather a short peak in life satisfaction among football affine groups.
\end{abstract}

Keywords Well-being $\cdot$ Happiness $\cdot$ Emotion $\cdot$ Mega sport-events $\cdot$ Football

Electronic supplementary material The online version of this article (https://doi.org/10.1007/s11482-0189599-y) contains supplementary material, which is available to authorized users.

Michael Mutz

michael.mutz@sport.uni-giessen.de

1 Department of Sport Science, Justus-Liebig-University Giessen, Kugelberg 62,

Gießen 35394, Germany 


\section{Sport Consumption and Subjective Well-Being}

Much research has shown that leisure-time sports activities are related to subjective well-being (SWB) and psychological health (Bize et al. 2007; Gillison et al. 2009; Schmiedeberg and Schröder 2017). The SWB effect of leisure has been justified by claiming that leisure activities satisfy a person's basic needs and growth needs, for instance, a need for relatedness, aesthetic and mastery experiences, distinction, health etc. (Sirgy et al. 2017). It can be argued that respective effects are produced by active sports participation. However, only few studies have addressed how the passive consumption of sport events in the media relates to SWB. Some authors have convincingly shown that witnessing athletic success of a favoured team is associated with positive emotions among fans and supporters (Kerr et al. 2005; Jones et al. 2012). However, it is less clear if such experiences spill-over to general life satisfaction. Such a "bottom-up spill-over effect" has been claimed to exist (Newman et al. 2014; Sirgy et al. 2017), namely that singular positive leisure experiences first increase satisfaction in leisure life and then generalize to a person's satisfaction with life as a whole.

Many sporting events are only relevant for a relatively small number of fans and supporters and may at best affect SWB in a small group. Only few events, in Germany for instance Olympic Games, FIFA World Cups and UEFA European Championships, are popular enough to have the potential to influence SWB at the national level. So far, studies which analysed the impact of international sporting success for well-being in a whole country have mostly came up with mixed findings (Elling et al. 2014; Kavetsos and Szymanski 2010; Kavetsos 2012; Van Hilvoorde et al. 2010) or failed to provide evidence that the presumed happiness effect exists (Pawlowski et al. 2014).

This paper is concerned with the possible effects of a major international sporting event on life satisfaction in Germany. Theoretically, it can be argued that SWB is heightened whenever the sport event leads to emotional, symbolic or social benefits. Firstly, international sport events can be regarded as contrasting to the perceived monotony of everyday life. According to Elias and Dunning's (1993) seminal works on leisure in modern society, a deep-rooted need for excitement has emerged in modernity, as modern life usually proceeds in predictable, rational and routinized ways. Sport events may offer an escape from these routines and provide the extra dose of excitement, arousal and emotionality modern individuals are longing for. Secondly, it seems plausible to assume that success of national athletes at international sporting events is related to symbolic benefits. Sirgy et al. (2017) argue that symbolic benefits can be reaped from leisure activities that symbolize a person's social self. Given that many spectators of international sport events identify with athletes who represent their own nation, it seems very likely that success of these athletes strengthens a person's social identity. Research on 'basking in reflected glory' (Cialdini et al. 1976; Jensen et al. 2016) provides ample evidence for this assumption. Hence, happiness can result from identification with victorious athletes and teams. Thirdly, watching international sporting competitions may also foster a person's sense of relatedness, given that such events are often watched together with others, for instance, family and friends or even in public spaces, bars, pubs, and Fan Fests (Rowe and Baker 2012). Hence, leisure pursuits which involve socializing and provide a sense of belonging satisfy social needs and, in turn, foster SWB (Sirgy et al. 2017). Hence, it can be claimed with some plausibility that international sporting events can 
potentially affect the well-being of at least some people in a country and - maybe under specific conditions - of a nation as a whole, too.

The present study investigates the relationship between the 2016 UEFA EURO and life satisfaction in a nation-wide longitudinal study carried out in Germany. It is based on a Germany-wide representative panel study, where each respondent was questioned before, during and after the 2016 UEFA EURO. Given that Germany is Europe's biggest football market and football the unquestioned number-one sport in the country, the EURO may indeed have the potential to affect life satisfaction among Germans. However, if any general, nation-wide effect on SWB exists, the large-scale study presented here further allows specifying effects for various sub-groups, i.e. for fans and supporters vs. those uninterested in the football event. The panel design, the representativeness of the sample and the exact timing of the data collection over the course of the EURO are unique characteristics of the present study. These characteristics and procedures allow for more reliable conclusions (compared to previous studies) regarding the relationship between major sporting events and life satisfaction. Moreover, the inclusion of a third measurement point two months after the EURO allows for assessing the longevity of any sport-related effect on life satisfaction.

\section{State of Research}

One of the main constructs in SWB research is life satisfaction, usually conceived as a cognitive and rather stable judgement of individual life quality (Diener et al. 1999; Schimmack 2008). However, prior studies point to the reactivity of life satisfaction ratings to incidental daily occurrences (Emmons and McCullough 2003; Reis et al. 2000), situational conditions (Gamble and Gärling 2012; Kämpfer and Mutz 2013; Schwarz and Clore 1983) or single events like vacations and holidays (De Bloom et al. 2012; Gilbert and Abdullah 2004; Mutz 2016). Hence, there is an ongoing debate about potential impacts of single events on individual ratings of life quality.

\section{Hosting Major Sporting Events and Well-Being}

These debates are also prevalent in the domain of sport where sociologists and economists have increasingly addressed the relationship between major sport events and life satisfaction. However, studies have provided mixed and inconclusive results. Some studies have addressed the effects of hosting a major sport event on well-being. It was demonstrated that life satisfaction increases at country level when this country is hosting a major sport event like the Olympic Games or the FIFA World Cup (Kavetsos and Szymanski 2010; Kavetsos 2012). Positive effects of hosting such events are also detectable at the individual level. Two studies have shown that South Africans perceived the FIFA 2010 World Cup to have increased community spirit, pride and wellbeing (Gibson et al. 2014; Kaplanidou et al. 2013). Similar results were found in Sydney after the 2000 Olympic Games (Waitt 2003). Smaller gains in subjective wellbeing were reported for residents of Rio de Janeiro after the FIFA World Cup 2014, but only if they perceived the atmosphere during the event positively (Pfitzner and Koenigstorfer 2016). However, this effect lasted for less than three months. Finally, Londoners reported increased levels of happiness and life satisfaction during the 
Olympic Summer Games 2012 compared to a baseline measure one year before (Dolan et al. 2016). Moreover, the London data are also compared to a control group of residents from Berlin and Paris, whose life satisfaction did not increase considerably during the 2012 Olympics. This design lends additional support to the notion that hosting the event has caused the effect.

\section{(National) Athletic Success and Well-Being}

Although major sport events may have a high potential for increasing well-being in the host country, this is, admittedly, a very rare occasion for many nation states. Some studies have thus focused on the potential role of athletic success. In a German study, it was reported that two thirds of the Germans agree with the statement 'I am happy if German athletes win many medals at Olympic Games or World Championships' (Hallmann et al. 2013). A Dutch study points to a small, short-term increase in SWB during the 2010 FIFA World Cup, where a surprisingly strong Dutch national team advanced to the tournament's final (Elling et al. 2014). However, other major sport events (e.g. 2008 Olympic Games, 2008 UEFA EURO) did not affect well-being in The Netherlands. Using several waves of the Eurobarometer surveys, Kavetsos (2012) showed that nations which reached higher stages in the UEFA EURO 2000 reported significantly larger levels of life satisfaction afterwards. However, the assumed feelgood effect of national athletic success finds little support in a recent analysis based on data from the International Social Survey Programme (ISSP), were sporting success was not directly linked to well-being (Pawlowski et al. 2014). Likewise, Doerrenberg and Siegloch (2014), using data of unemployed people from several waves of the German Socio-Economic Panel (SOEP), did not find support for the notion that football tournaments positively impact life satisfaction. Instead, they even find a rather strong negative effect of such tournaments in the case of unemployed men.

Studies following the 'willingness-to-pay'-paradigm are based on the assumption that the experiential value of sporting success can be expressed in monetary terms: The higher the amount of money subjects are inclined to pay in a hypothetical scenario that assumes that voluntary monetary contributions would guarantee sporting success, the greater the symbolic and emotional value they attach to sporting success. Germans, for instance, would pay 26 Euro, on average, to see Germany winning the FIFA World Cup (Wicker et al. 2012) and about 6 Euro, on average, for a first rank of Germany on the medal table of Olympic Games (Wicker et al. 2012). It is concluded from these findings that national success in sport generates happiness and pride in the population. However, it is a matter of debate whether or not willingness to pay for victories is a valid measure for happiness.

\section{Emotional and Psychological Correlates of Well-Being}

Other research has focused on emotions. Studies have shown that witnessing sporting success of athletes of the own nation increases patriotic pride (Elling et al. 2014; Mutz 2013; Mutz and Gerke 2017; Van Hilvoorde et al. 2010; Von Scheve et al. 2014). Moreover, it was demonstrated that identification with athletes and sport teams is associated with reduced feelings of loneliness and alienation (Branscombe and Wann 1991; Wann et al. 2005; Wann and Pierce 2005). Research has further shown a steep 
increase in negative emotions, particularly depression and anger, in English football fans after the elimination of their national team in the 2010 FIFA World Cup's Round of Last 16 (Jones et al. 2012). In the same study, a reduction in negative affect has been demonstrated among Spanish supporters when their national team advanced to the final and won the World Cup. A study among supporters of Japanese football teams suggests that wins leads to positive emotions among fans whereas a loss foster negative emotions (Kerr et al. 2005). Further evidence for the emotionality associated with sports comes from a study demonstrating that losses of local football teams are associated with increasing rates of family violence (Card and Dahl 2011). Hence all these studies lend support to the notion that sport events may impact on SWB by triggering positive or negative emotions in individuals.

\section{Aims of the Present Study}

The study at hand contributes to the state of research especially because methodological shortcomings of prior studies were avoided. Prior research on the relationship of sporting success with happiness and life satisfaction has mainly applied crosssectional research designs, which cannot account for causality. Hence, panel studies are called for (Hallmann et al. 2013). When existing large-scale data sets are used, another problem occurs: Many respondents are interviewed weeks or months after a particular sport event, so that any effect on life satisfaction that may have existed during the event may have weakened considerably. Hence, studies should assess well-being ideally during or immediately after a mega-sport event. Dohmen et al. (2006), for instance, have conducted one of the very few surveys with exactly timed interview periods embracing the 2006 FIFA World Cup. Finally, the longevity of any sportinduced well-being effect has seldom been investigated - usually due to a lack of panel data including a follow-up measure.

The present study avoids such methodological shortcomings and can thus provide more reliable data on the relationship between sporting events and life satisfaction. It is based on a Germany-wide representative panel study, where each respondent was questioned before, during and after the 2016 UEFA EURO. Three assumptions guided this research: First, it is hypothesized that life satisfaction increases during the EURO at the national level.

- $H \# 1$ : Self-reported life satisfaction among Germans is higher during the 2016 UEFA EURO compared to some weeks before the tournament.

However, it is assumed that any sport-induced effect on well-being should be more pronounced among those segments of the population who are interested in football. Those with indifference towards football are not considered to have a markedly heightened satisfaction with life during the EURO and may thus form a natural control group.

- H\#2: The increase in life satisfaction is more pronounced in individuals with greater affinity to football compared to those individuals who are indifferent towards football. 
Given that studies critically discuss the longevity of sports effects on well-being (Elling et al. 2014; Dolan et al. 2016), it seems worthwhile to investigate inasmuch any initial well-being effect of sporting success can be sustained over two months. Therefore, the hypothesis is tested, if life satisfaction after the EURO is still elevated compared to the period before the event.

- H\#3: Self-reported life satisfaction among Germans is higher two months after the 2016 UEFA EURO compared to some weeks before the tournament.

Of course, these hypotheses only make sense as long as the German national football team performs rather successfully at the EURO. However, the German team performed well during the competition with four wins and one draw in the first five matches. Moreover, their style of play was considered attractive and confident by many observers. Only in the semi-finals the team was narrowly defeated by the French team. Therefore, the EURO has proceeded rather successfully from a German point of view, so that above-mentioned hypotheses seem justified.

\section{Methods}

\section{Study Design}

This study was part of a larger research project on the public perception of mega-sport events in Germany ("Mega sport-events and their effects on collective identifications in the nation-state"). As part of this project, an online panel study around the 2016 UEFA EURO was realized. Specifically, a representative sample was questioned by a webbased questionnaire (CAWI), which respondents were able to answer on personal computers, tablets and mobiles. Representativeness was accomplished by integrating the study into an existing nation-wide online panel survey. Access to this survey was provided by Infratest dimap, a leading organization in public opinion polling and political consultation in Germany. The first assessment was carried out from May 9 to May 24, hence 18 to 33 days prior to the beginning of the UEFA EURO 2016 in France $(t 1)$. The second point of measurement was during the UEFA EURO $2016(t 2)$. However, respondents at $t 2$ were not questioned all at the same time, but in six time slots covering the whole tournament and the week immediately following the tournament (see Fig. 1). This procedure ensures that the responses extend over the whole tournament and results are not biased by particular events during the competition. The third assessment started about eight weeks after the end of the UEFA EURO and took place from September 19 to September 30, $2016(t 3)$.

\section{Sample}

The initial sample size in $t 1$ was $N=1556$. The initial sample represents the adult population living in Germany ( $>18$ years) and matches the composition of the population according to age, gender, educational level and residency (Tab. 1, column 1 and 2 ). From the initial sample $N=853$ respondents $(55 \%)$ could also be approached at $t 2$ as well as $t 3$. However, 47 cases had to be eliminated from the resulting panel data set, 


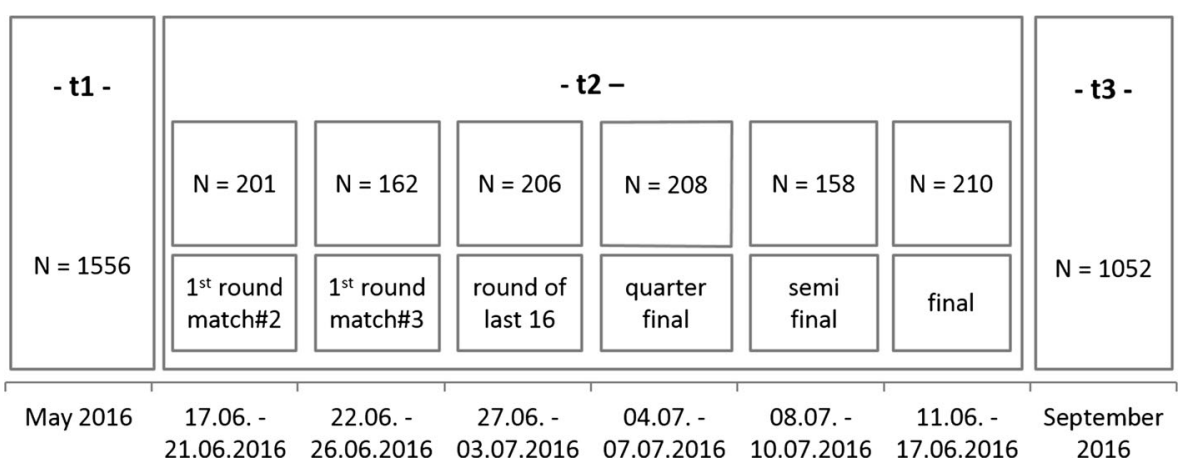

Fig. 1 The longitudinal design of the survey. Note: Indicated are the realised interviews; 250 interviews were scheduled in each time slot in $t 2$

as a low overall response time indicated that these respondents did not fill out the questionnaire thoroughly. After these data cleaning procedures, a final sample of $N=$ $806(52 \%)$ remained for the analyses.

\section{Panel Attrition}

Panel attrition is regarded as a major concern in longitudinal samples as it leads to reduced generalizability of the findings (e.g. Fitzgerald et al. 1998). One particular reason for attrition is that some groups of respondents cannot be reached easily or may

Table 1 Representativeness of the sample according to gender, age, education and residency

\begin{tabular}{llll}
\hline & Population parameters ${ }^{\mathrm{a}}$ & initial sample $(t 1$ only $)$ & $\begin{array}{c}\text { final panel sample } \\
(\mathrm{t} 1+\mathrm{t} 2+\mathrm{t} 3)\end{array}$ \\
\hline $\begin{array}{l}\text { Gender } \\
\text { male }\end{array}$ & & $51.2 \%$ \\
$\quad$ female & $48.3 \%$ & $48.5 \%$ & $48.8 \%$ \\
Age & $51.7 \%$ & $51.5 \%$ & $10.9 \%$ \\
$18-29$ & & & $19.9 \%$ \\
$30-44$ & $16.7 \%$ & $15.9 \%$ & $31.3 \%$ \\
$45-59$ & $22.1 \%$ & $21.5 \%$ & $37.9 \%$ \\
$>60$ & $28.5 \%$ & $27.8 \%$ & $35.3 \%$ \\
Education & $32.7 \%$ & $34.8 \%$ & $33.7 \%$ \\
lower secondary & $38.3 \%$ & & $31.0 \%$ \\
medium secondary & $31.1 \%$ & $36.9 \%$ & $17.6 \%$ \\
higher secondary & $30.6 \%$ & $32.9 \%$ & $82.4 \%$ \\
Residency & & $30.2 \%$ & \\
East Germany & $17.5 \%$ & $17.3 \%$ & \\
West Germany & $82.5 \%$ & $82.7 \%$ & \\
\hline
\end{tabular}

${ }^{a}$ Population parameters are calculated from German census data, published by the Federal Statistical Office of Germany (www.zensus2011.de) 
lose interest in participating in later waves of the survey. To assess inasmuch nonrandom attrition exists in the present study, (non-)participation at $t 2$ and $t 3$ was correlated with a range of demographic and substantial variables (gender, age, education, immigration background, satisfaction with life, interest in football broadcasts) collected at $t$. These analyses reveal that the final sample matches the main parameters of the adult population living in Germany (see Table 1) with two exceptions: Higher attrition rates were found for younger people who are slightly underrepresented in the panel data set. Moreover, attrition was correlated with interest in TV football $-51 \%$ of respondents with low interest but 59\% of respondents with high interest in TV football, according to $t 1$ answers, are represented in the final data set. Although the attrition bias is generally rather low and has not seriously distorted the representativeness of the sample, inverse probability weights were still calculated and used in the analyses to adjust for selectivity based on age and interest in TV football (Kalton and Kasprzyk 1986). However, all analyses in this paper were also performed with non-weighted data for comparison reasons and these analyses show that inclusion of weights did not impact on any of the results.

\section{Measures}

1) Life Satisfaction was measured with the conventional, well established question, 'On the whole, how satisfied or not are you with the life you lead'. Respondents could indicate their satisfaction on a 10-point rating scale with higher values indicating higher satisfaction. Life satisfaction scores were collected in all three waves, which allows for comparisons over time. In all waves, the question on life satisfaction has been placed prior to the questions related to the UEFA EURO in order to prevent football-related halo effects. Further on, so-called 'focussing effects' (Dolan and Metcalfe 2010), resulting from respondent's remembrance of previous waves, should be low, given the distance of time between the three surveys.

2) Interest in football broadcasts was measured with the question 'How much are you interested in football broadcasts on television'. The question did not refer to the German team in particular, but addressed general interest in football on TV. The question was part of the survey at $t$. Answer categories for respondents were 'strongly', 'somewhat', 'hardly' and 'not at all'. Those who selected 'strongly' or 'somewhat' for their answer were labelled 'football consumers' and form the football interested group of respondents $(59 \%)$. Those who answered 'hardly' and 'not at all' are categorized as not interested in TV football (41\%).

3) German team identification was measured with the question 'Do you identify with the German national football team'. Answer categories again ranged from 'strongly', 'somewhat', 'hardly' to 'not at all'. Those who identify 'strongly' or 'somewhat' were considered sympathizers of the German team (69\%) and those who selected 'hardly' and 'not at all' form the group of the non-sympathizers (31\%).

4) Consumers of live TV broadcasts involving the German national team at the UEFA EURO can be identified as another indicator for football affinity. Respondents were shown a list of all matches of the German national team at the EURO that had been broadcasted up to the time of the survey and were then asked to mark all matches for which the 'live broadcast' had been watched 'in full length'. Due to 
the fact that the survey at $t 2$ involved six different time slots, the list of matches differed between these slots. Therefore, the measure used here simply distinguishes those respondents who did watch at least one match live and in full length (67\%) vs. those who did not watch a single live broadcast (33\%).

Unsurprisingly, the three measures for football affinity - namely, general football interest, German team identification, and TV consumption - are correlated with each other. All correlations are in the range between $\varphi .=47$ and $\varphi=.54$ and can thus be considered medium to large. However, it still seems worth to consider all three measures in the analyses, in order to check the robustness of the findings against the peculiarities of a specific operationalization.

5) Covariates in the Generalized Linear Models (GLM) are gender, age, educational level (in three groups, see Tab. 1) and immigration background. Immigration background refers to first and second generation immigrants. Moreover, a dummy variable was included which accounts for possible bias from summer vacations. The variable separates respondents who have been on summer vacation shortly before or at the time of the $t 2$ survey from the rest. These covariates were selected as all five may possibly influence football consumption as well as life satisfaction and may thus bias the results, if not controlled for.

\section{Analytical Approach}

To assess differences between the pre-EURO life satisfaction scores $(t 1)$ and the within-EURO $(t 2)$ as well as post-EURO life satisfaction scores $(t 3)$, pairedsample $t$-test were run for the entire sample as well as subgroups of football interested and football disinterested respondents. Changes in mean values and the statistical significance of the changes are reported. Generalized linear models (GLM) for repeated measurements were then run to test for the hypothesized difference in the change of life satisfaction over time between respondents with football affinity vs. respondents with indifference towards football (time* group interactions). Additional OLS regression analyses were calculated to estimate changes from t 1 to $\mathrm{t} 2$ and $\mathrm{t} 3$ in specific groups. These analyses - which produced highly similar results - are included in an online appendix supplementing this paper.

\section{Results}

\section{Changes in Life Satisfaction during the UEFA EURO (t1 to t2)}

Mean values for life satisfaction reveal that respondents are very satisfied with their life. In the present sample, life satisfaction scores at $t 1(M=7.10, S D=1.94), t 2(M=7.37$, $S D=1.77)$ and $t 3(M=7.20, S D=1.79)$ are close to those values usually measured in the German population (Organisation for Economic Co-operation and Development 2015). T-tests for mean comparisons between $t 1$ and $t 2$ reveal a 
significant change in life satisfaction among subjects (Table 2, upper row). During the UEFA EURO, respondents indicated significantly more life satisfaction compared to some weeks before $($ Diff $=.27 ; d=.17 ; p<.001)$. According to Cohen's rule of thumb (Cohen 1992), this difference represents a small effect. Further ANOVA revealed that life satisfaction at $t 2$ did not vary with the date of the interview $\left(F=1.25 ; \eta^{2}=.05\right.$; $p=.17)$. Hence, the general increase of life satisfaction is not due to a single match but can be found throughout the whole tournament.

Hypotheses \#1 thus finds support in the data. However, there are manifold possible approaches on how to interpret the depicted increase in life satisfaction at $t 2$. It may reflect, as hypothesized, the collective joy triggered by athletic success at the EURO 2016 in France, but may also be due to the beginning of the summer, the start of the holiday season or other singular events unrelated to the football competition. Therefore, analyses were calculated separately for respondents who are interested in the EURO and those who are indifferent towards the tournament. Three indicators were selected for this purpose: a) general interest in TV football, b) identification with the German national team, and c) consumption of the live broadcast of the German team on TV. For all three indicators highly consistent results are revealed (Table 2).

First, it is shown that during the EURO life satisfaction increases significantly among those who are generally interested in football broadcasts (Diff $=.35 ; d=.21$; $p<.001)$. There is also an increase among those indifferent towards football broadcasts (Diff $=.16 ; d=.11 ; p=.044)$, however this change in life satisfaction is much smaller. Second, a significant increase of life satisfaction is indicated for sympathizers of the German national football team (Diff $=.39 ; d=.24 ; p<.001)$, but not among those who identify hardly or not at all with the German team (Diff $=.04 ; d=.03 ; p=.648)$. Third, those who have viewed the live broadcast of (at least) one match of the German team in full length also report a higher level of life satisfaction compared to the weeks prior to

Table 2 Life satisfaction: Mean values and changes during the UEFA EURO 2016 from $t 1$ to $t 2$

\begin{tabular}{|c|c|c|c|c|c|c|}
\hline & \multicolumn{2}{|c|}{ Life satisfaction } & \multirow[b]{2}{*}{ Diff } & \multirow[b]{2}{*}{$S D_{\text {diff }}$} & \multirow[b]{2}{*}{$d$} & \multirow[b]{2}{*}{$p$} \\
\hline & $t 1$ & $t 2$ & & & & \\
\hline Full sample & 7.10 & 7.37 & 0.27 & 1.58 & 0.17 & $<.001$ \\
\hline \multicolumn{7}{|l|}{ Interest in football broadcasts } \\
\hline strongly/somewhat & 7.11 & 7.46 & 0.35 & 1.65 & 0.21 & $<.001$ \\
\hline hardly/not at all & 7.09 & 7.25 & 0.16 & 1.46 & 0.11 & .044 \\
\hline \multicolumn{7}{|l|}{ Identification w/ German team } \\
\hline strongly/somewhat & 7.05 & 7.44 & 0.39 & 1.63 & 0.24 & $<.001$ \\
\hline hardly/not at all & 7.22 & 7.26 & 0.04 & 1.41 & 0.03 & .648 \\
\hline \multicolumn{7}{|l|}{ TV broadcast of last match } \\
\hline viewers (live, full length) & 7.13 & 7.50 & 0.37 & 1.50 & 0.25 & $<.001$ \\
\hline non-viewers & 7.07 & 7.14 & 0.07 & 1.71 & 0.04 & .504 \\
\hline
\end{tabular}

Indicated are mean values at $t 1$ and $t 2$, the change from $t 1$ and $t 2$ (diff), the standard deviation of individual changes $\left(S D_{\text {diff }}\right)$, the effect size Cohens $d$ and the significance of the change $(p)$ 
the UEFA EURO (Diff $=.37 ; d=.25 ; p<.001)$. For non-viewers, the increase in life satisfaction is much weaker and insignificant (Diff $=.07 ; d=.04 ; p=.504$ ). Hence, our hypothesis \#2 finds much support: Satisfaction of life increases among those groups interested in football in general and in the UEFA EURO in particular, whereas mostly marginal and insignificant changes are seen among respondents with limited interest in football.

Additionally, General Linear Models (GLM) for repeated measurements were run. This procedure tests for the significance of time* group interactions, hence whether or not changes among respondents with football affinity from $t 1$ to $t 2$ differ from the changes among uninterested respondents. Moreover, the GLM analyses also allow to control for possible confounding factors, namely gender, age, educational level, immigration background and, most importantly, summer vacations. Three GLM models were calculated. They reveal a significant time*group interaction for those who identify with the German national team vs. those who do not $(F=8.88 ; p=.003)$ as well as for those who have watched a live broadcast of the German team vs. those who did not $(F=8.04 ; p=.005$; see also Fig. 2$)$. The time* group interaction for those interested vs. those uninterested in football broadcasts was marginally significant $(F=3.70$; $p=.055$ ). All of the other interactions (with gender, age, educational level, immigration background and summer vacations) were insignificant in the three models. Overall, it can be concluded from these findings that life satisfaction has increased to a greater degree in football affine groups during the EURO 2016 compared to groups indifferent towards football (H\#2).

\section{Changes in Life Satisfaction after the UEFA EURO (t1 to t3)}

Mean comparisons between $t 1$ and $t 3$ do only point to a marginal increase in satisfaction with life (Table 3, upper row) which fails to reach the .05 significance level (Diff $=.10 ; d=.06 ; p=.077)$. Hence, the increase in life satisfaction found during the UEFA EURO was not persistent: The effect substantially declined at $t 3$, about two months after the tournament. Hence, the assumption of persistency over the course of two months is rejected (H\#3).

This effect is also found when football affine groups are analysed separately (Table 3): Two months after the EURO life satisfaction is still somewhat higher among those who are generally interested in football broadcasts (Diff $=.13$; $d=.08 ; p=.075)$, who sympathize with the German national football team (Diff $=.16 ; d=.10 ; p=.014)$ and viewed the live broadcast of (at least) one match of the German team in full length (Diff $=.15 ; d=.10 ; p=.020)$. However, compared to the increased life satisfaction during the EURO, the level at $t 3$ is already considerably lower. The EURO effect on life satisfaction has thus lost substantially in its magnitude. Mean comparisons for the respondents with lesser interest in football and the EURO show that life satisfaction in this group has almost exactly returned to the baseline level from May 2016.

Moreover, similar GLM analyses as for the $t 1$ to $t 2$ period were also calculated for the $t 1$ to $t 3$ period. These models reveal no significant time*group interactions. Hence, changes in life satisfaction from $t 1$ to $t 3$ found in football affine groups are not significantly different from changes in groups disinterested in football (see also Fig. 2). 

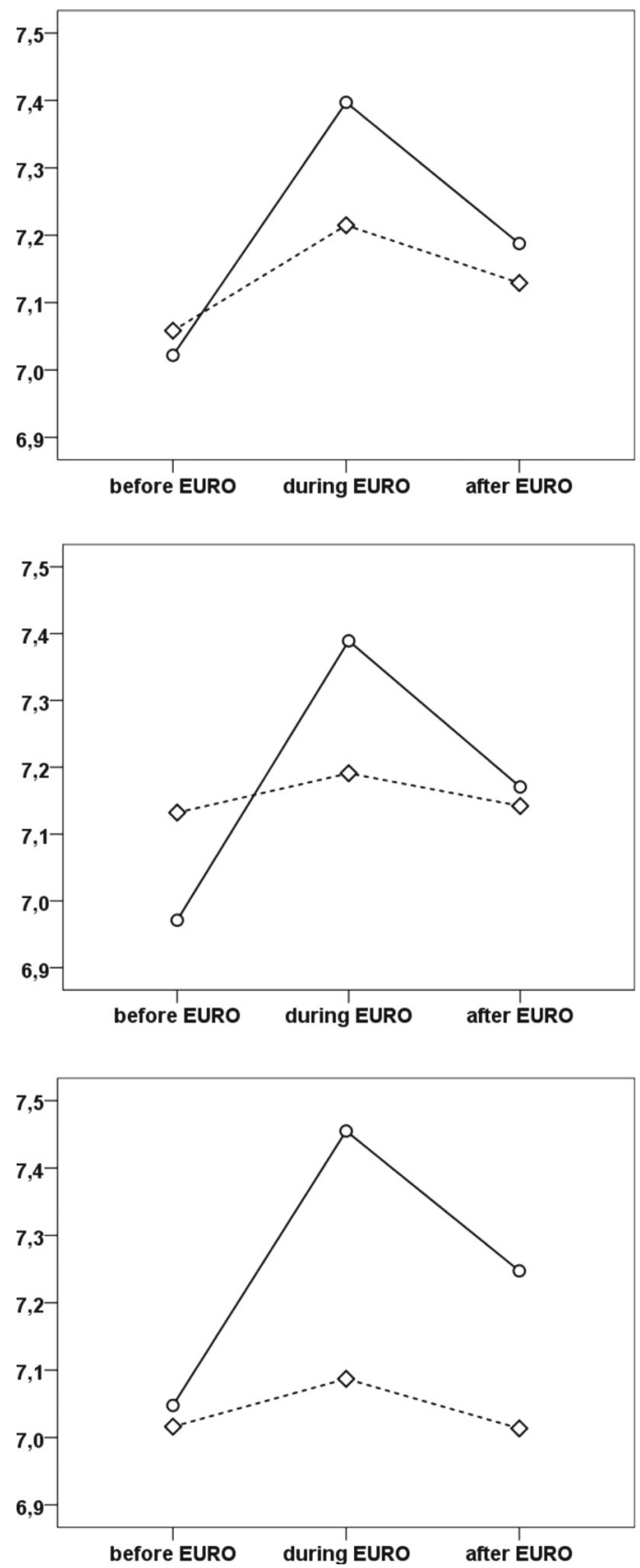

a Interest in football broadcasts

$\bigcirc$--- interested in TV football

$\diamond$ - - disinterested in TV football

IA $t 1-t 2: \mathrm{p}=.055$

IA $t 1-t 3: \mathrm{p}=.399$

b Identification with German team

$\bigcirc---$ high identification

$\diamond$ - - low identification

IA $t 1-t 2: \mathrm{p}=.003$

IA $t 1-t 3: \mathrm{p}=.111$

$\bigcirc---$ watched live broadcast(s)

$\diamond$ - - did not watch live broadcast

IA $t 1-t 2: \mathrm{p}=.005$

IA $t 1-t 3: \mathrm{p}=.085$

Fig.2 Estimated marginal means for satisfaction with life: Time*group interactions for groups with higher vs. lower interest in football and in the German national football team. Note: Models include controls for gender, age, education, immigrant background and summer vacation 
Table 3 Life satisfaction: Mean values and changes after the UEFA EURO 2016 from $t 1$ to $t 3$

\begin{tabular}{|c|c|c|c|c|c|c|}
\hline & \multicolumn{2}{|c|}{ Life satisfaction } & \multirow[b]{2}{*}{ Diff } & \multirow[b]{2}{*}{$S D_{\text {diff }}$} & \multirow[b]{2}{*}{$d$} & \multirow[b]{2}{*}{$p$} \\
\hline & $t 1$ & $t 3$ & & & & \\
\hline Full sample & 7.10 & 7.20 & 0.10 & 1.55 & 0.06 & .077 \\
\hline \multicolumn{7}{|l|}{ Interest in football broadcasts } \\
\hline strongly/somewhat & 7.11 & 7.24 & 0.13 & 1.62 & 0.08 & .075 \\
\hline hardly/not at all & 7.09 & 7.13 & 0.05 & 1.44 & 0.03 & .568 \\
\hline \multicolumn{7}{|l|}{ Identification w/ German team } \\
\hline strongly/somewhat & 7.05 & 7.22 & 0.16 & 1.55 & 0.10 & .014 \\
\hline hardly/not at all & 7.22 & 7.19 & -0.03 & 1.53 & -0.02 & .793 \\
\hline \multicolumn{7}{|l|}{ TV broadcast of last match } \\
\hline viewers (live, full length) & 7.12 & 7.27 & 0.15 & 1.47 & 0.10 & .020 \\
\hline non-viewers & 7.06 & 7.05 & -0.01 & 1.70 & -0.01 & .956 \\
\hline
\end{tabular}

Indicated are mean values at $t 1$ and $t 3$, the change from $t 1$ and $t 3$ (diff), the standard deviation of individual changes $\left(S D_{\text {diff }}\right)$, the effect size Cohens $d$ and the significance of the change $(p)$

\section{Discussion and Conclusions}

Based on a Germany-wide representative panel study around the UEFA EURO 2016, it was demonstrated that life satisfaction was significantly higher during the football tournament compared to some weeks before (H\#1). However, the overall effect size must be considered as small $(d=.17)$. The study further buttresses the notion that football effects on well-being are more pronounced among those individuals interested in football $(\mathrm{H \# 2})$. In football affine groups life satisfaction increased markedly during the EURO $(d \geq .21)$, whereas changes in life satisfaction were mostly insignificant and marginal in size among respondents uninterested in football $(d \leq .11)$. It can be concluded from these results that only those sports events can potentially affect well-being in a country which are followed by the large majority of the population. For minor sports events the same mechanisms may apply, however only a small segment of the population gets emotionally affected and may thus judge their life somewhat better. Hence, only few major events are popular enough to affect well-being in a nation.

Moreover, the present study gives some empirical clues on the longevity of effects. Some scholars have argued that increased levels of well-being and pride that result from sporting success do not last for long and start to vanish shortly after a sport event is over (Elling et al. 2014; Pfitzner and Koenigstorfer 2016). The data presented here buttresses this notion and, at the same time, reject the assumption of persistency $(\mathrm{H \#} 3)$. Sporting success seems to trigger short-term eruptions of happiness that start to decline quickly after the end of the event. This finding may also help explaining inconsistent results of previous studies. Some studies with insignificant results have focused on surveys, where the majority of the respondents were interviewed weeks or even months after a sport event (Pawlowski et al. 2014; Kavetsos and Szymanski 2010). Hence, these studies must assume that well-being effects of major sport events can be 
preserved over longer periods. Such an assumption, however, cannot be buttressed by empirical data presented here: The magnitude of effects decreased considerably even among supporters and fans only two months after the EURO. Increased happiness may thus be considered a by-product but not a 'legacy' of sporting success.

The findings come with implications for sport organizations and policy-makers: High-performance sport is extremely costly. The belief in sports' societal benefits and its capacity to enhance public welfare are frequently utilized as key arguments for legitimizing state subsidies of high performance sports (e.g. Atkinson et al. 2008; Hallmann et al. 2013). Besides international reputation und prestige, national pride and happiness are often-quoted outcomes of national sporting success at mega sporting events. Data presented here generally underpins this rationale by showing that intangible assets as, for instance, life satisfaction, can be produced by sports. However, as the well-being effect seems to be non-sustainable, it is a matter of debate whether or not the collective joy of a few weeks is worth the money invested.

Finally, this study provides further insights on the reactivity of life satisfaction measures with regard to single events. The construct theoretically aims at a stable, long-term and rational evaluation of life quality. Despite such claims, however, life satisfaction is closely associated with current emotional states (Schimmack 2008). Individuals report a higher satisfaction with life in situations where they feel positive and they are less satisfied with their life in situations that induce negative feelings (Schwarz and Clore 1983). Hence the degree of reactivity that was shown here is likely to be triggered by the emotions induced by this particular sports event. This reasoning is in line with previous research which has shown that survey responses generally are influenced to some degree by current emotions, may they be triggered by football (Dohmen et al. 2006) or any other external event (Kämpfer and Mutz 2014).

As a matter of course, the results of the German team at the EURO 2016 could not be manipulated in this study. Many observers in Germany concluded that although the public perception of the performance of the German team was rather positive, the public celebrations during the tournament were not as euphoric as seen in prior tournaments and the number of visitors at official Fan Fests was declining. Hence, the emotional well-being generated by the EURO 2016 for the public was considered lower compared to prior tournaments. There may be a number of reasons for this declining spirit: It may be due to the high expectations among German fans after the German team had won the World Cup in 2014. Psychologists have shown that expected wins are emotionally less satisfying compared to unexpected wins (Vandello et al. 2007). Furthermore, the press coverage of the UEFA EURO was long dominated by fan riots - for instance, those on the opening weekend in Marseille -, reports of (insufficient) security measures in the stadia and fears concerning possible terrorist attacks. This may have blurred the atmosphere, too. Finally, the increased number of participating countries and the new competition system with more teams being progressed to the knockout stage has led to a number of matches which were considered less suspenseful and mediocre in playing quality, particularly during preliminary rounds. Keeping this in mind, the EURO 2016 must be considered a rather conservative test case for assessing the well-being effects of football events in Germany. Replications of this research approach are thus of vital importance, not least to see whether effects are depending on the peculiarities of a single tournament. 
Acknowledgements This work was part of the research project "Mega sport-events and their effects on collective identifications in the nation-state". It has been supported with a research grant from the German Federal Institute of Sport Science [070904/16-17].

\section{Compliance with Ethical Standards}

Conflict of Interest The author declares that he has no conflict of interest.

Ethical Approval All procedures were in accordance with the ethical standards of the national research committee and with the 1964 Helsinki declaration.

Open Access This article is distributed under the terms of the Creative Commons Attribution 4.0 International License (http://creativecommons.org/licenses/by/4.0/), which permits unrestricted use, distribution, and reproduction in any medium, provided you give appropriate credit to the original author(s) and the source, provide a link to the Creative Commons license, and indicate if changes were made.

\section{References}

Atkinson, G., Mourato, S., Szymanski, S., \& Ozdemiroglu, E. (2008). Are we willing to pay enough to 'back the bid'? Valuing the intangible impacts of London's bid to host the 2012 summer Olympic games. Urban Studies, 45(2), 419-444.

Bize, R., Johnson, J. A., \& Plotnikoff, R. C. (2007). Physical activity level and health-related quality of life in the general adult population: A systematic review. Preventive Medicine, 45(6), 401-415.

Branscombe, N. R., \& Wann, D. L. (1991). The positive social and self-concept consequences of sports team identification. Journal of Sport \& Social Issues, 15(2), 115-127.

Card, D., \& Dahl, G. (2011). Family violence and football: The effect of unexpected emotional cues on violent behavior. Quarterly Journal of Economics, 126(1), 103-143.

Cialdini, R. B., Borden, R. J., Thome, A., Walker, M. R., Freeman, S., \& Sloan, L. R. (1976). Basking in reflected glory: Three (football) field studies. Journal of Personality and Social Psychology, 34(3), 366375.

Cohen, J. (1992). A power primer. Psychological Bulletin, 112(1), 155-159.

De Bloom, J., Geurts, S. A. E., \& Kompier, M. A. J. (2012). Effects of short vacations, vacation activities and experiences on employee health and well-being. Stress and Health Journal, 28(4), 305-318.

Diener, E., Suh, E., Lucas, R. E., \& Smith, H. (1999). Subjective well-being: Three decades of progress. Psychological Bulletin, 125(2), 276-302.

Doerrenberg, P., \& Siegloch, S. (2014). Is soccer good for you? The motivational impact of big sporting events on the unemployed. Economics Letters, 123(1), 66-69.

Dohmen, T., Falk, A., Huffman, D.\&Sunde, U. (2006). Seemingly Irrelevant Events Affect Economic Perceptions and Expectations: The FIFA World Cup 2006 as a Natural Experiment. IZA Discussion Paper No. 2275. Institute for the Study of Labor.

Dolan, P., Kavetsos, G., Krekel, C., Mavridis, D., Metcalfe, R., Senik, C., Szymanski, S.\&Ziebarth, N.R. (2016). The Host with the Most? The Effects of the Olympic Games on Happiness. DIW Discussion Paper, 1599. Berlin.

Dolan, P., \& Metcalfe, R. (2010). 'Oops...I did it again': Repeated focusing effects in reports of happiness. Journal of Economic Psychology, 31(4), 732-737.

Elias, N., \& Dunning, E. (1993). Quest for excitement: Sport and leisure in the civilizing process. Oxford: Basil Blackwell.

Elling, A., van Hilvoorde, I., \& van den Dool, R. (2014). Creating or awakening National Pride through sporting success: A longitudinal study on macro effects in the Netherlands. International Review for the Sociology of Sport, 49(2), 129-151.

Emmons, R. A., \& McCullough, M. E. (2003). Counting blessings versus burdens: An experimental investigation of gratitude and subjective well-being in daily life. Journal of Personality and Social Psychology, 84(2), 377-389. 
Fitzgerald, J., Gottschalk, P., \& Moffitt, R. (1998). An analysis of sample attrition in panel data: The Michigan panel study of income dynamics. The Journal of Human Resources, 33(2), 251-299.

Gamble, A., \& Gärling, T. (2012). The relationships between life satisfaction, happiness, and current mood. Journal of Happiness Studies, 13(1), 31-45.

Gibson, H. J., Walker, M., Thapa, B., Kaplanidou, K., Geldenhuys, S., \& Coetzee, W. (2014). Psychic income and social capital among host nation residents: A pre-post analysis of the 2010 FIFA world cup in South Africa. International Journal of Tourism Management, 44, 113-122.

Gilbert, D., \& Abdullah, J. (2004). Holidaytaking and the sense of well-being. Annals of Tourism Research, 31(1), 103-121.

Gillison, F. B., Skevington, S. M., Sato, A., Standage, M., \& Evangelidou, S. (2009). The effects of exercise interventions on quality of life in clinical and healthy populations; a meta-analysis. Social Science \& Medicine, 68(9), 1700-1710.

Hallmann, K., Breuer, C., \& Kühnreich, B. (2013). Happiness, pride and elite sporting success: What population segments gain most from national athletic achievements? Sport Management Review, 16(2), 226-235.

Jensen, J. A., Turner, B. A., James, J., McEvoy, C., Seifried, C., Delia, E., Greenwell, T. C., Ross, S., \& Walsh, P. (2016). Forty years of BIRGing: New perspectives on Cialdini's seminal studies. Journal of Sport Management, 30(2), 149-161.

Jones, M. V., Coffee, P., Sheffield, D., Yangueez, M., \& Barker, J. B. (2012). Just a game? Changes in English and Spanish soccer fans' emotions in the 2010 world cup. Psychology of Sport and Exercise, 13(2), 162-169.

Kalton, G., \& Kasprzyk, D. (1986). The treatment of missing survey data. Survey Methodology, 12(1), 1-16.

Kämpfer, S., \& Mutz, M. (2013). On the sunny side of life: Weather effects on life satisfaction. Social Indicators Research, 110, 579-595.

Kämpfer, S., \& Mutz, M. (2014). Der Einfluss positiver und negativer Stimmungen von Befragten auf ihr Antwortverhalten in politischen Meinungsumfragen [The influence of positive and negative mood on political judgments in public opinion polls]. Politische Vierteljahresschrift, 55(2), 268-294.

Kaplanidou, K., Karadakis, K., Gibson, H., Thapa, B., Walker, M., et al. (2013). Quality of life, event impacts, and mega-event support among south African residents before and after the 2010 FIFA world cup. Journal of Travel Research, 52(5), 631-645.

Kavetsos, G. (2012). National Pride: War minus the shooting. Social Indicators Research, 106(1), $173-185$.

Kavetsos, G., \& Szymanski, S. (2010). National well-being and international sports events. Journal of Economic Psychology, 31(2), 158-171.

Kerr, J. H., Wilson, G. V., Nakamura, I., \& Sudo, Y. (2005). Emotional dynamics of soccer fans at winning and losing games. Personality and Individual Differences, 38(8), 1855-1866.

Mutz, M. (2013). Patrioten für drei Wochen. Nationale Identifikation und die Fußball-EM 2012 (Patriots for three weeks: National identification and the European football championship 2012). Berliner Journal für Soziologie, 22(4), 517-538.

Mutz, M. (2016). Christmas and subjective well-being: A research note. Applied Research in Quality of Life, 11, 1341-1356.

Mutz, M., \& Gerke, M. (2017). Major sporting events and national identification. Communication \& Sport. https://oi.org/10.1177/2167479517733447.

Newman, D. B., Tay, L., \& Diener, E. (2014). Leisure and subjective well-being: A model of psychological mechanisms as mediating factors. Journal of Happiness Studies, 15, 555-578.

Organisation for Economic Co-operation and Development. (2015). How's life? 2015: Measuring well-being. Paris: OECD publishing.

Pawlowski, T., Downward, P., \& Rasciute, S. (2014). Does national pride from international sporting success contribute to well-being? An international investigation. Sport Management Review, 17(2), 121-132.

Pfitzner, R., \& Koenigstorfer, J. (2016). Quality of life of residents living in a city hosting mega-sport events: A longitudinal study. BMC Public Health, 16, 1102.

Reis, H. T., Sheldon, K. M., Gable, S. L., Roscoe, J., \& Ryan, R. M. (2000). Daily well-being: The role of autonomy, competence, and relatedness. Personality and Social Psychology Bulletin, 26(4), 419-435.

Rowe, D., \& Baker, S. A. (2012). The "fall" of what? FIFA's public viewing areas and their contribution to the quality of public life. Space and Culture, 15(4), 395-407.

Schimmack, U. (2008). The structure of subjective well-being. In M. Eid \& R. J. Larsen (Eds.), The science of subjective well-being (pp. 97-123). New York: Guilford Press.

Schmiedeberg, C., \& Schröder, J. (2017). Leisure activities and life satisfaction: An analysis with German panel data. Applied Research in Quality of Life, 12(1), 137-151.

Schwarz, N., \& Clore, G. L. (1983). Mood, misattribution, and judgements of well-being: Informative and directive functions of affective states. Journal of Personality and Social Psychology, 45(3), 513-523. 
Sirgy, M. J., Uysal, M., \& Kruger, S. (2017). Towards a benefits theory of leisure well-being. Applied Research in Quality of Life, 12(1), 205-228.

Van Hilvoorde, I., Elling, A., \& Stokvis, R. (2010). How to influence National Pride? The Olympic medal index as a unifying narrative. International Review for the Sociology of Sport, 45(1), 87-102.

Vandello, J. A., Goldschmied, N. P., \& Richards, D. A. R. (2007). The appeal of the underdog. Personality and Social Psychology Bulletin, 33(12), 1603-1616.

Von Scheve, C., Beyer, M., Ismer, S., Kozlowska, M., \& Morawetz, C. (2014). Emotional entrainment, National Symbols, and identification: A naturalistic study around the Men's football world cup. Current Sociology, 62(1), 3-23.

Waitt, G. (2003). Social impacts of the Sydney Olympics. Annals of Tourism Research, 30(1), 194-215.

Wann, D. L., \& Pierce, S. (2005). The relationship between sport team identification and social wellbeing: Additional evidence supporting the team identification-social psychological health model. North American Journal of Psychology, 7(1), 117-124.

Wann, D. L., Walker, R. G., Cygan, J., Kawase, I., \& Ryan, J. (2005). Further replication of the relationship between team identification and psychological well-being: Examining non-classroom settings. North American Journal of Psychology, 7(3), 361-366.

Wicker, P., Hallmann, K., Breuer, C., \& Feiler, S. (2012). The value of Olympic success and the intangible effects of sport events - a contingent valuation approach in Germany. European Sport Management Quarterly, 12(4), 337-355.

Wicker, P., Prinz, J., \& von Hanau, T. (2012). Estimating the value of national sporting success. Sport Management Review, 15(2), 200-210. 